\title{
A Decade of Rural Research: What have We Learnt about Adult Language, Literacy and Numeracy?
}

\author{
Chris Atkin \\ Faculty of Education, Liverpool Hope University \\ Hope Park, Liverpool, L16 9JD \\ Tel: 44-0151-291-3801Ｅ-mail: atkinc@hope.ac.uk
}

\begin{abstract}
The role of functional literacy, linked to employment, leads to a narrow view of rural learners' need both economically and socially. The drive for individuals to take responsibility for their own learning and development is, indeed, a good thing. However, the burden of guilt felt by those who are unable, or unwilling, to achieve the standards set out in the Skills for Life (DfEE, 2001) strategy, is significant. This deficit model of applied functionality is likely to result in a fracturing of traditional social networks upon which much of rural life is constructed, leading to social fragility. The changing character of the English countryside with its rising population drawn from urban and international migration is striking and certainly challenges the caricature of a white, male, middle-class countryside. With these changes comes a demand for an alternative curriculum which reflects the large number of older learners and the language, literacy and numeracy (LLN) needs of both an established labour market and a new international workforce.
\end{abstract}

Keywords: Rural learners, Lifelong learning, Functional literacy

\section{Introduction}

This article is informed by a series of research projects carried out by members of the UNESCO Centre for Comparative Education Research at the University of Nottingham (Atkin, 2009; O'Grady and Atkin, 2009; Atkin and O'Grady, 2006a; Atkin and O'Grady 2006b, 2006; O'Grady and Atkin, 2006; Morgan and Atkin, 2006; Atkin, Rose and Shier, 2005; Atkin and Merchant, 2004). The precise focus for much of the research has been the impact of the Skills for Life strategy (DfEE, 2001) to raise standards of adult literacy and numeracy by policy makers. However rural learners, whilst recognised within the strategy, are often disadvantaged because the small population numbers tend to mask 'deprivation' indices favouring urban populations:

'People with literacy and numeracy difficulties are geographically spread across the country. Ours is therefore a national strategy, recognising that potential learners may live in rural areas as well as in inner-city estates. But we also know that people with poor literacy and numeracy are particularly concentrated in deprived areas. There are around 1.7 million adults with literacy deficiencies living in the $10 \%$ most deprived wards. Our national strategy must therefore include clearly targeted, area-based measures for tackling poor literacy and numeracy skills among these communities.' (DfEE, 2001:31)

The strategy has become synonymous, both in policy and practice, with notions of functional literacy, including numeracy, and their association with engagement in the economy through employability (DfEE, 2001). A key question for rural policy makers is whether this link with employment, which is often framed around an urban model of employment type and format, is appropriate within a rural context. Functional literacy in this context is inevitably linked to a deficit model which sets out to assess an individual's lack of ability rather than their existing literacy skills (Barton, 1994).

In this article I address directly this construction of literacy, defined by the DfE (formerly the DfES and DfEE) as 'the ability to read, write and speak in English and to use mathematics at a level necessary to function at work and in society in general' (DfEE, 2001: passim). Other conceptual understandings of literacy include a social practice approach to literacy which places a higher emphasis on understanding literacy practices within the social and cultural contexts of everyday life (referred to as 'New Literacy Studies' by supporters of this approach, including Gee, 1999, Barton and Hamilton, 1998, Street, 1993) and more recently the approach to literacy as text with multi modality and multi literacies. This model supports the argument that language should be seen as just one of several modes through which communication is conducted and sees literacy practices as one set amongst many communicative practices, including diagrams, objects, notational systems, in addition to language in either its spoken or written forms: 
'We suggest that, like language, visual images, gesture and action have been developed through their social usage into articulated or partly articulated resources for representation. Individuals make choices from the 'representational resources' available amongst these various modes and a multi-model perspective enables us to identify the traces of these decisions - of the interests of the parties to text.'

(Kress and van Leeuwen, 2001:43)

These alternative understandings of literacy all have merit in helping us to understand forms of literacy and identity in rural areas, particularly in their acceptance that ethnographic - whole culture - approaches are often the most helpful for policy makers and practitioners in providing contextually relevant curricula offers.

In focusing on the government's notion of functional literacy I would not wish to turn my back on these holistic approaches to literacy; more to recognise that the realities of policy and practice are currently driven by the development, and assessment of, functional literacy for employment.

My research has been driven by a series of recurrent questions and assumptions used here to structure this article:

How do we conceptualise rural?

Is a 'one size fits all' approach to curriculum and funding appropriate for rural learners?

How are learners perceiving and experiencing learning e.g. what is seen as legitimate? (Has lifelong learning - in all its forms - become a new imperialism?)

Is there a relationship between Language, Literacy and Numeracy (LLN) skills and social fragility?

Do every day practices support, or impede, what is learned in structured programmes e.g. what is the relationship between everyday life and the formal curriculum?

\section{Context}

In this article I report on a range of issues affecting adult post-school learners living in rural areas of the East Midlands region of England. Although much of the research included rural communities across England I draw specifically on examples taken from the East Midlands. The most rural county within the East Midlands is Lincolnshire; more specifically Eastern and Southern Lincolnshire. Lincolnshire is one of six counties which form this government region and represents around $48 \%$ of the East Midlands land mass, yet only $15.5 \%$ of its population. In common with other rural areas of England, Lincolnshire has seen rapid growth in its population of 9.4\% between 1991 and 2001 (Office for National Statistics, 2002); the largest percentage increase in the East Midlands region. This increase has largely consisted of older people retiring, or returning to, Lincolnshire, attracted by low house prices and pleasant market towns. When compared to the rest of the East Midlands region Lincolnshire has more than twice the percentage of its working population employed directly in agriculture. Despite this, agriculture and fishery account for only $1.4 \%$ of employment (Government Office for the East Midlands, 2007) with further linked employment located in the agricultural service and food processing industries, raising this figure to around nine percent of the counties employment (Atkin and Merchant, 2004). Later in this chapter we report on the changing face of employment within these sectors as numbers of oversees workers locate to rural England.

As Figure 1 shows the geography of the East Midlands is predominantly rural, yet its population and economy is often associated with the urban wards shown to the west of the region. This is particularly true for the area dominated by the so called 'golden triangle' of Derby, Leicester and Nottingham. The regions to the north and west of Nottingham also contain many ex-mining communities which have suffered as their traditional mining base has declined over the last thirty years. These communities often form 'urban islands' within the otherwise rural seas of north Nottinghamshire and north east Derbyshire. The Countryside Agency map of the East Midlands, shown below, identifies the striking division of urban and rural wards:

Insert Figure 1 Here

\subsection{How do we conceptualise rural?}

In 2004 the UK government introduced a new system for defining 'rural' consisting of two parts: the settlement morphology, comprising all places under 10,000 population encompassing small ('rural') towns, villages and scattered dwellings; and, the wider geographical context in which individual settlements are located i.e. whether the wider area is defined as being 'sparsely' populated or not in line with Defra's minimum density criteria of households across areas of radius 10,000m, 20000 m and 30,000m (Defra, 2004: 53). 
The new definition combines elements of geographical context and social structures. In considering these two conceptual positions we suggest the following typology.

\subsection{Rural as a geographical construct}

Small scale - small schools, small villages, small churches, small communities

Isolated - separated from services and amenities (also safer by dislocation from urban settings)

A product of agriculture and its environmental activity

Infrastructure - Management and governance of local services e.g. Local Health

Limited employment opportunities

(Atkin, 2003)

These characteristics refer to the physical context of rurality rather than any reference to the nature of rural society. The association with land, the physical environment, is a common theme in many studies of rural life around the world - see as examples Geertz 1961 and, more recently, Sinclair 2002 - the relationship between cultural identity and the land appears strong and lasting.

\subsection{Rural as a social construct}

Strong community feeling, friendlier than urban communities, tighter knit - the anthropological issue of kinship and literacies

Conservative and traditional values

A slower, less pressurised way of life

A feeling of 'us' and 'them'. (See Lewis's (1985) introduction to Social Anthropology in Perspective in which he makes the point that we find it much easier to say what we are not.)

(Atkin, 2003)

This second typology addresses the nature of rural people rather than the place itself. Although these are 'an abstraction of place they are also durable, individual characteristics likely to persist in another setting' (Atkin, 2003:8). As many people dealing with refugee communities will testify. The scale of village life and the interdependence of apparently different sections of the community certainly play an important part in the sense of belonging; not unique to rural village life but often reinforced by media representations of rural for example in programmes such as Heartbeat and Peak Practice. For rural communities, with all their diversity, the search for a sense of belonging rooted to the land and community is often linked to identity and goes someway to explaining the desire of 'incomers' to link themselves to local organisations such as the Church, the 'Women's Institute' or the parent-teacher association of the local school. Linked to this rural identity is often a localised legitimacy (Atkin and Merchant, 2004) for skills and knowledge, particularly the value of physical rather than intellectual skills. It might be argued that rural culture is masculine in many of its characteristics.

In my research I have tended to rely heavily on social constructions of rural rather than geographically determined definitions. This is particularly useful in other rural contexts where large population movements are common for example men of working age in parts of rural Africa, and it makes far more sense for us to consider rural communities as social constructs, rather than simply a link to place. This individual perception of rural identity is a very ethnographic approach to definitions of rural, relying on methods which seek to identify the cultural root; the big picture. These are almost always multi method, interpretive and rely heavily on people's perspectives of their realities of life.

Accordingly, observations, in-depth and extended interviews were used as the major sources of data for the projects reviewed in this chapter. Participants were encouraged to reflect and explore their learning experiences within a holistic context. In addition, quantitative data was used to support the findings and produce a contextual setting for the findings.

\subsection{Is a 'one size fits all' approach to curriculum and funding appropriate for rural learners?}

Two of the research programmes funded by the National Research and Development Centre for adult literacy and numeracy (NRDC) included Lincolnshire as a research site and addressed this question directly (Atkin and Merchant, 2004, and, Atkin, et al., 2005). The evidence would suggest that the balance between a curriculum offer that provides local relevance for rural learners yet provides access to a national framework, which allows, indeed promotes a hierarchy of progression routes through qualifications, requires further thought from local and 
national policy makers. In rural England LLN provision in both the formal and non-formal sectors is extensive, complex, diverse and in a state of constant change.

Those delivering LLN programmes in rural areas face many of the same issues as those in urban areas but certain factors exacerbate these challenges. Whilst 'rurality' was clearly a consideration for those forming and implementing policy it was also an integral part of their delivery. Rurality was taken as a given obstacle that they were constantly trying to overcome. In line with the findings of many of those who contributed to Landscapes of Learning (Jones, 2002), the main challenges to the provision of training included viable numbers, transport, access, the availability of qualified tutors, working patterns and childcare. The real and perceived inflexibility and target-driven nature of Learning and Skills Council (LSC) funding was highlighted by many as an issue in rural areas. Rural outreach programmes were said to be difficult to maintain without the guarantee of a minimum number of learners. Many providers highlighted a lack of core-funding resulting in a great deal of time and resource being expended to seek alternative funding, particularly since much of the funding was short-term in nature. The short-term nature of funding also made it difficult for providers to plan for the future and, in some cases, to provide a consistent, quality service to the learner.

The geography of rural areas certainly impacts on provision in the ways identified above but I would suggest that the social construction of rural also influences adult education provision; and LLN provision in particular. The link between LLN and rural identity, caricatured by the public perception of rural labour demands is being challenged as new technology becomes the norm in agriculture and as new high-technology industries relocate to rural areas of England, encouraged by increasingly developed communication systems, affording high connectivity to many rural and semi-rural areas, and a vision of a safer, cleaner environment for the workforce.

The evidence from research reported here would suggest that interest in and concern for, adult literacy and numeracy among senior personnel, owners, executives, directors, managers, senior administrators, in small and medium businesses in rural areas is very limited. The majority claim to view the literacy and numeracy of their employees as 'adequate', 'good' or 'excellent'. Only $4 \%$ of the employers questioned, regarded the literacy levels of their employees as 'poor' and only 6\% regarded their numeracy levels as 'poor' (Atkin and Merchant, 2004).

However, it is not possible to assume a standard or sophisticated understanding of the status of 'literacy' and 'numeracy' through this framework. Almost all employers assessed literacy and numeracy in relation to specific work practices, in keeping with the current emphasis on functional literacy. Literacy and numeracy are not seen by employers as having an inherent value; they are regarded as valuable only in relation to current employment tasks or requirements. Literacy and numeracy in themselves are not seen as attractive forms of economic, social or cultural capital; employees have no 'interest' or 'illusio' (Bourdieu, 1998: 76-77) in being more literate and/or numerate. Lack of interest in literacy and numeracy is described as self-perpetuating, durable and difficult to interrupt, like habitus (Jenkins, 1998: 79; Mahar, et al., 1990: 11). In Bourdieu's terms, those not 'caught up in and by the game' of literacy and numeracy cannot see that 'playing is worth the effort' (Bourdieu, 1998: 76-77). Although this again is not unique to rural learners, it does raise the broader question of why LLN skills are seen as such an indicator of the economic potential of society. Some interviewees linked this lack of interest in, and valuing of, literacy and numeracy to a rural economy which, though changing, still presents an image of low-paid, seasonal, practical, manual work linked to tourism, leisure or agriculture.

'Others linked lack of interest to a closed, homely, limited society and cultural environment which comforts but suppresses aspiration; a lack of opportunities for cultural consumption (art galleries, theatres, etc.) tends to create satisfaction and contentment rather than curiosity, ambition and intellectualism.' (Atkin and Merchant, 2004:63)

In other words, people are unlikely to see the importance of literacy and numeracy in a social and cultural world which often lacks the economic and social opportunities to use new skills, including higher levels of LLN (Atkin, et al., 2005). Some respondents in our research argued strongly against an understanding of the rural setting as different or 'special' in relation to literacy and numeracy. Others constructed the rural environment as positive in opposition to a construction of the urban setting as negative, disadvantaged, more illiterate and innumerate. There is evidence, in some responses, of defensiveness; a weariness with and annoyance at negative constructions of rural 'disadvantage'. Many employers and employees sighted staff loyalty and a rural work ethic as much more important than LLN targets.

Where LLN provision was seen as appropriate provision the importance of being sensitive to issues of 'stigma' was highlighted as important. 'Embarrassment', 'stigma' and 'awkwardness' around adult literacy and numeracy were discussed by respondents in relation to rural geographies of social closeness, visibility and lack of anonymity. 
'Two contrasting solutions were suggested: attempts to make adult literacy and numeracy training private, secret or hidden in other kinds of adult education; or an attempt to make adult literacy and numeracy training widespread, common, familiar and every day, rather than novel, special and exceptional.' (Atkin and Merchant, 2004: 64)

The research reported above suggests that the funding issue in rural areas of England is largely an issue of geography while curriculum is one of social; social in the sense of culture and economy. This is where the difficulties begin for policy makers who appear wedded to notions of equity in terms of provision rather than the appropriateness of provision and opportunity. The direct link between functional literacy and the economy makes it impossible to separate out the Skills for Life policy from the wider rural regeneration agenda, dominated by the current focus on skills.

\section{Perceptions and experiences of LLN Learners}

The following section draws on the Atkin, et al., (2005) research which focused on LLN learner and tutor experiences across rural England. Rural learners gave several reasons for initially attending provision including a desire to help their children; to enable them to do their job more effectively or to gain promotion at work; to help them get a job or do further studies; to increase their confidence; because they were referred by another agency; or to enable them to cope with everyday tasks such as paying bills, going shopping or filling in forms. Others came along because they'd missed out at school and had reached a point in their lives where they decided it was time to improve their skills.

'I need to do it before I do further studies, get the basics in place.'

'My daughter (aged 9) when she brings homework home you can't do, it's a bit embarrassing.

'It's something I've always wanted to do - to prove to myself that I could do it.'

Learners on programmes for English for speakers of other languages (ESOL) often gave similar reasons for motivation. In addition, many simply wanted to improve their English so that they could cope with everyday life in England and be able to communicate more effectively with others in their community.

'One reason for starting the class was to read the notices in the office, bus times, percentage of people off etc, forms, health and safety.'

'I can talk to people in the town. I understand them and they understand me.'

Learners gave a wide range of responses when asked what difference the course had made to their lives, or what they hoped to achieve by doing the course. In many cases, soft outcomes, such as confidence building and the opportunity for social interaction, were important to the learner. Other responses were similar to that given for their initial reason for attending. Examples included: to get a qualification; to gain promotion or to get a job; or to be able to help their children with school work. The following quotes illustrate some of the ways provision had changed learners' lives.

'I booked a holiday in London via the travel agents, never done it before.'

'I have been able to help my daughter [with school work] I wouldn't have been able to before. I have more confidence.

'I can now read to my children. A couple of years ago I could not read. I'm more confident and am now able to do training at work.'

'I want to get GCSEs in maths and English because I would like to get work as a bank cashier or secretary.'

'It has completely changed my life. I have much more confidence - I feel I can do things now. Now I want to become a basic skills tutor - to give something back - to help others.'

Learners were asked why they had chosen the particular course and venue; predominantly courses sourced through the adult and community sector. Many chose the provision because it was local and sometimes the only option. Word of mouth, i.e. recommendation by a friend, family member or referral by a third party such as a social worker, was the main way of attracting new learners. Some said they had seen or heard the course advertised. A few respondents had found, or thought they would find, courses provided by further education colleges too intimidating and one or two said they had deliberately chose provision outside their village or town so that people did not recognise them. An interesting contrast to the caricature of urban anonymity.

'I found it a bit frightening going to the college.'

'Didn't want to go there in case I came across anyone I knew, used to travelling when you live in Lincolnshire. 
Most learners were very happy with their tutor, praising their teaching ability, patience and understanding and would recommend courses to others. A number had persuaded family, friends or colleagues to attend.

'Explains it well, doesn't leave you behind.'

'Not like school, everyone equal, don't feel stupid.'

'They've got time for you.'

'Absolutely brilliant! They believe in you.'

'They make it fun. I used to hate maths at school. I was made to feel stupid if I didn't understand.'

Further analysis showed that, in rural areas, accessibility and flexibility are crucial for successful provision. Due to varying shift patterns and seasonal work provision needed to be at a time and location convenient to the learner and this could change from week to week. This has often been seen in an agricultural context but more recently seasonality is linked to the demands of the tourist industry. Other factors mentioned included: tutors who were well qualified, experienced and able to empathise with learners; the importance of the learner feeling comfortable and the need to make learning relevant to individuals.

Examples of comments regarding these factors:

'Rural provision is carefully thought out to make allowance for busy times on the farms.....i.e. lambing season very few farmers will wish to attend training events or to sit exams etc. at that time.'

'Community based provision not only means that the transport problem is resolved but also means that provision can be variable based on the particular needs of that community...'

'The fact that the centre is used for many community activities therefore it is part of people's lives.'

To offer provision at a local venue; make it an enjoyable experience; relate it to real situations such as supporting children with schoolwork.'

Well documented issues of access, cost, transportation, childcare and the fear of learners becoming visible in small communities are real concerns for many wishing to access provision in rural England. Travel issues also affect the delivery of provision, as does the problem of getting sufficient numbers to make courses viable. Geographic barriers were also mentioned in relation to progression routes for learners.

Travel:

'This is a rural area with a scattered population, and many of those who might most benefit are unable to travel to centres'

'Rural area, small groups, lots of travelling to various sites. The practicalities of talking all your resources with you e.g. laptop, books, files etc.'

'Very limited due to geography. There are colleges in main towns but public transport is inadequate.'

Learner numbers:

'The size of the population is such that there are few places where viable groups are possible; this is not helped by transport difficulties.'

Fear and stigma:

'Everyone knows everyone - stigma attached to 'skills for life' learning'

Other barriers:

Other barriers cited include a lack of awareness of available provision or that provision was free; lack of motivation; cultural perceptions; concern over a general lack of awareness of what LLN skills encompasses and a lack of qualified tutors - this last barrier was a particular concern for provision providers. Reasons given for the lack of motivation by learners included the slow or limited progression and employment opportunities in rural areas, leading to a belief that there was no value in up-skilling. Furthermore, some potential learners had enjoyed successful careers or had led a 'full life' in spite of low literacy or numeracy skills, either by developing coping strategies or by choosing a lifestyle that did not depend on these skills. There was also where some respondents did not accept the need for universal literacy; 'after all not everyone can play the piano'.

'They don't see any benefit in changing how they currently get thru' life'

'Need acknowledged but low down on priorities.' 
'Local employers have not fully recognised the value of the national test....they do not ask for the qualification when they advertise jobs. Learners are not motivated to work towards the national test because they don't see the immediate value to their working lives.'

'Low expectations; the belief that you don't need qualifications for manual work.'

'Apathy of some long-term unemployed people.'

Both policy makers and tutors involved in this project (Atkin, et al., 2005) identified partnership working either as an important aspect of successful provision or as a strategy being used to overcome barriers to access provision. In contrast, lack of partnership working, or competition for the same learners, was identified as a barrier or funding issue.

'Close working with learning partnership groups to ensure continuity and blanket cover.'

'A co-ordinated approach from all providers rather than everyone looking for the same business.'

'The problem of competition for few learners means that centres are under-funded...'

'Lots of money/time has to be expended to develop business often with little/no return; often other providers simultaneously doing the same!'

Important strategies used to promote and raise awareness of training provision included increased publicity, short 'taster' training sessions and development work in the community and the workplace.

'Closer ties to local community through visits to inform. Try to build ESOL groups by word-of-mouth throughout communities.

'Get out into the community - talk to groups - offer bite size courses as tasters, as much publicity as possible including local press and radio and word of mouth.'

Linked closely with barriers to learning and provision, a recurring common funding issue were problems that were associated with a sparse population.

'Minimum number of students for economical breakeven is difficult - we work to the same funding criteria as inner city provision although both settings have very diverse needs.'

'The funding doesn't take into account the cost of travel/time/equipment and the 1:1 nature.....no economy of scale.'

'Hard to get enough groups to be cost effective - in rural locations and in small workplaces. It should be possible to fund smaller groups. Colleges will not come out to small towns because not cost-effective, but Basic Skills students are often those without own transport.'

According to practitioners, the demand for ESOL provision in many rural areas had increased rapidly over a short period of time (12-18 months). This was largely attributed to increasing numbers of migrant workers settling in rural areas, but also partly as a result of government refugee dispersal programmes, leading to the settlement of refugees in rural areas rather than their historical association with urban areas. Also, some members of rural communities who had been established in England for a number of years were accessing ESOL provision for the first time. The low numbers of ESOL learners in rural areas often resulted in provision not being offered. The transient nature of some ESOL learners and the varying work patterns, incorporating unsociable or long hours, also created barriers to the effective provision of appropriate programmes; as did the lack of qualified ESOL tutors since demand in this area has traditionally been low or non-existent. Some providers were able to describe innovative and creative ways to overcoming these barriers through, for example, training ESOL learners to become ESOL tutors and increasingly flexible session times.

'Migrant workers often stay weeks rather than months. Scattered population.'

'No established communities for foreign language speakers, through which learners can hear about ESOL provision.'

'Immigrant workers work long hours therefore time to learn is difficult.'

'Classes spread over a week both am and pm to meet the learners needs as many work in restaurants and require a choice of attendance.'

All areas were trying to develop provision in the workplace. However, in many areas progress was reported as being slow and time consuming. Much of the necessary preparatory work was poorly funded or not funded at all. Learning brokers employed by the Local Authority or college and Trade Union Congress Learning Representatives were being used in several areas across England to access workplace learning with varying 
degrees of success. Employers were often reluctant to engage in educating employees, especially in smaller companies where it was more difficult to release employees at busy times.

'Retention drops as companies get busy e.g. Christmas in food industry.'

'Workplace basic skills under development. Building links with employers challenging due to high percentage of small and medium enterprises (SMEs).'

The demand for ESOL provision in rural areas of the East Midlands, and England in general is increasing year on year. Our research in 2004 highlighted the range of nationalities present in rural England's migrant workforce.

'ESOL learners came from 28 different countries and had been in this country for anything between 2 weeks and 41 years, challenging stereotypical notions that the need for ESOL provision is solely an 'off the boat' issue applicable to asylum seekers. Indeed, nearly a third of those interviewed (30\%) had lived in England for over five years. Eight learners had been resident in the UK for over ten years with two learners, a husband and wife, residing for 41 years.' (Atkin, et al., 2005: 59)

The nationalities of ESOL learners interviewed in the 2004 study are shown below in Table 1.

Insert Table 1 Here

The diversity and numbers of foreign nationals in rural England is itself a force for change as business and cultural provision follows this new market opportunity into rural areas. Since Atkin, et al's work in 2005 the number of foreign workers entering rural England has continued to rise and with the exception of 2006-07 (when equal number of foreign workers entered and left Lincolnshire) continues to rise year on year. The biggest group of recent arrival are from the A8 countries: Poland, Slovakia, Czech Republic, Slovenia, Lithuania, Latvia, Hungary and Estonia. The East Midlands is one of the regions in the UK that has seen a massive rise in the number of these migrants seeking to live and work in the region. (thisisLincolnshire, 2010: Lincolnshire Echo)

A number of practitioners felt that there were no differences between numeracy and literacy in terms of barriers to learning. Among those who did identify a difference, issues of motivation and stigma or acceptability were given as the main factors. Many interviewees felt it was more socially acceptable to admit poor numeracy skills than poor literacy skills. Reasons for motivation to learn, or lack of it, were linked to various factors such as past experience and the perceived relevance of learning.

'Numeracy is seen as a difficult subject and personal barriers because of past experience seem to be greater than those perceived by those who study literacy.'

'Many not so bothered with numeracy, either because they feel it is not so important to them, or they are frightened to try. Fear of failure is a big barrier, so is the feeling that they simply do not need numeracy to find work'

'Literacy in more pertinent to adults in their everyday lives.'

\section{Is there a relationships between LLN skills and social fragility?}

The focus of the Skills for Life strategy on literacy and numeracy as skills precludes the opportunity to consider them as social and cultural practices which present in multiples forms as part of our day to day lives (Papen, 2005). Literacy, in this context can be reframed as an activity that is carried out, rather than as an attribute residing in the person (Barton and Tusting, 2005). Literacy, from a social practice perspective, is not considered merely as a skill but as something that people do (Papen, 2005).

Central to a social practice view of literacy is the notion that literacy comes in many forms; literacies become distinct in their differing uses for differing purposes and in differing contexts; they are always embedded in a social and cultural context and always involve people in some way (Barton, 1994, Papen, 2005): a social network.

It seems clear that rural society would benefit from developing a more flexible approach to the delivery of the Skills for Life training programmes (Atkin \& Merchant, 2004; Atkin, et al., 2005). This idea embraces the concept of learner persistence presented in the work by Porter, et al., (2005). Their work draws on findings from Young, et al., (1994) who found that learners often did not participate in programmes long enough to reap substantial learning gains. Rural learners are nothing if not persistent and a shift in policy which reflects the chaotic lives of adults in rural and urban settings could improve the life chances of many adult learners by not labelling learners as failures if they take a break from their studies to look after children, elderly family members or just feel - for the time being at least - they have learnt enough. The changing nature of rural identity and the 
many challenges this inevitably brings will itself challenge the social networks and historical alliances which have characterised many rural areas.

\section{Do every day practices support, or impede, what is learned in structured programmes e.g. what is the relationship between everyday life and the formal curriculum?}

In considering this question Atkin, et al., we explored the relationship of everyday literacy practices and the development of literacy skills for employment. This is the fundamental aspiration upon which the Skills for Life strategy was formed - that the development of literacy skills would increase employability and would enable individuals to engage more easily with their day-to-day literacy demands. The team have undertaken several research projects between 2005 and 2007 which consider this question.

During 2004/5 the NRDC asked the team to undertake an evaluation of resources constructed to support the development of literacy and numeracy skills within an embedded context. Whilst the concept of contextualising learning is not new and can be traced back to Dewey (1916), contextualising literacy and numeracy within vocational settings was innovative in the field. Emergent findings from the project found that making learning meaningful and relevant, contextualised to individuals' personal interests and employment did, indeed, enable learners to engage with the material in a more meaningful way and with interest and purpose.

During 2006 the Lincolnshire and Rutland LSC invited Atkin, et al., to work with practitioners to explore how national policies were 'playing out' in reality. Of particular interest to the LSC was the influence of such policies on a highly rural region of England. In order to answer this question the LSC were extremely anxious to undertake a piece of research; significantly however they were keen that this research should be a practitioner-led action research project which enabled both the learners and practitioners working with learners in rural communities and in rural settings to have a voice.

The aim of the project was to support the LSC to develop local policy responses to the learning needs of the Lincolnshire and Rutland population, based on well grounded, appropriately focused and contextualized research, which maximised the use of the funding allocation available. It was important for the LSC that the research was not driven by what was already known but, significantly, that they could hear from the ground issues facing practitioners and learners and that all stakeholders had an opportunity to inform the future of adult learning in Lincolnshire and Rutland. The major research question in this project was: What is the impact of policy on the adult learning environments of Lincolnshire and Rutland?

The proposal to undertake this project was disseminated widely throughout the county and practitioners from all areas of the post-16 sector were invited to submit proposals to the research team at the University of Nottingham for consideration in the project. Practitioners were advised that they would be supported through the research by the team at Nottingham through workshops, email, telephone communication and face-to-face visits.

The project required practitioners to construct a research proposal which would contribute a response to the overall research question. In submitting a research proposal, practitioners identified the context and aims of the proposed project, the proposed methodological approach of the project, including data collection and analysis. An outcome requirement of the overall project was that each research project should submit a written report for presentation to the Lincolnshire and Rutland LSC.

Several proposals were submitted to the research team. The proposals selected for inclusion in this project comprise:

1. ESOL learning outside the classroom: assessing it and improving it in Rural Lincolnshire

2. Adult Learners Responses to a relative lack of education opportunity in a rural setting

3. One year on - Did they take the Next Step? A practitioner led research report to investigate progress made by individuals one year after they have received Information and Advice relating to learning and work as part of the 'next-step' initiative.

4. Retention of ESOL students working in the food industry in South Lincolnshire

5. An exploration of the effectiveness of Reciprocal Reading within a group situation

6. What happened next? Has the national drive to reduce the number of learndirect providers had a negative impact on supporting hard-to-reach learners with literacy and numeracy issues?

7. When do I jump? A case study looking at career paths for potential new Skills for Life tutors?

These proposals highlight the range of concerns for those engaged in a variety of post-school education and training programmes across rural areas. The suggested topics clearly show the changing nature of rural 
communities reflecting employment opportunities and the diversity of the workforce. Interestingly, there is a broad range of teaching and learning experiences which were considered through the projects, including teaching in work-place environments, working with ESOL learners and the impact of the Skills for Life strategy (DfEE, 2001) on both the practitioners in relation to the professionalisation through qualifications and learners in relations to national core curricula. Intervention strategies aimed at supporting the up-skilling and employability of target groups within the population were also considered. Also interesting, is the willingness and eagerness of practitioners to be involved in such an innovative project which, arguably for the first time, enables them to influence and inform policy and practice directly.

Initial analyse from the tutors identified several significant points for policy makers, tutors and learners, which can be framed in part as a reflection of rural. These include:

Tutors fully support the Skills for Life strategy in striving to professionalise the workforce through a new suite of qualifications. However, living and working in a rural context problematises the practicalities of attending weekly teaching sessions and accessing practice opportunities is extremely difficult. Tutors did not want to be treated differently in terms of standards and expectations however, were keen to see the development of different models for accessing these qualifications. A blended learning approach was identified as a particularly good model because the construction of a 'community of practice' is considered to be an extremely important and valuable element of undertaking such qualifications.

The research proposal which considered ESOL provision in work placed learning, and particularly issues of retention found that $55 \%$ of those who start provision 'drop out' within five weeks. A major reason given for high dropout rates was the variable work patterns undertaken by learners and the fluid nature of employment. An outcome which confirms the findings of Atkin, et al., (2005). Findings published by researchers at the National Centre for the Study of Adult Learning and Literacy (NSCALL) also found that traditional patterns of attendance for adult literacy learners encouraged low achievement rates (Comings, et al., 1999). The high drop-out rates were due to a lack of flexibility which did not allow learners to take breaks from their learning in response to family or work commitments.

A further proposal considered how national policy decisions affected learners undertaking provision within an adult and community setting. The research found that following the withdrawal of learndirect contracts from small rural providers, many learners did not continue with their studies.

Finally, an intervention contracted to support people into training to achieve a Level 2 qualification and obtain employment through focused information, advice and guidance (IAG) session, was reviewed. The research considered the progression of individuals who had accessed such sessions over a four month period. On initial analyse it became clear that only one person had achieved a Level 2 qualification in the twelve months since the session had been received. However, significantly a number of learners had gained qualification at Entry 3 or Level 1 and were continuing to work towards Level 2 qualifications. Once again, this confirms the need to establish flexible training provision over extended periods of time which allow learners to access and re-enter training at times convenient to them and their lives.

The initial findings of these small-scale research projects reflect the shifting agenda which seeks local operationsalisation of national policy drawing on local solutions to broader policy questions. This repositioning mirrors the shift in thinking from liberal ideals of education for social development to education for economic independence.

\section{Conclusion}

The research informing this article suggests there are a range of challenges facing rural learners and education and training providers which in themselves may not be significantly different from those found in an urban context. Indeed many of the other articles in this journal are set within the very urban context of Hong Kong yet many of the challenges faced by those in rural Lincolnshire. What is perhaps fair to say is that rurality appears to exacerbate these challenges within a context of a changing social and economic landscape. Issues of rurality, both as a geographical and a social construct, are real and need to be considered by policy makers. Local solutions to the implementation of national policies, often constructed to focus on urban areas, must reflect the rural context. Following the publication of the rural white paper in 2000, government pledged to 'rural proof' (Countryside Agency, 2002) all policies in an attempt to ensure no departmental initiatives disadvantage rural communities. The challenge for policy makers going forward is to ensure financial restructuring - post credit crunch (2008) - ensures rural communities realise their potential for sustainable economic and social development. 


\section{References}

Atkin, C. (2003). 'The influence of rural culture on post-16 pathways from school' Journal of Continuing Liberal Adult Education, No. 24 July 2003 pp. 7-10.

Atkin, C. (2009). 'Literacies of power: A renaissance for adult education in an evolving world.' Indian Journal of Adult Education, Vol. 70, No. 1, pp. 3-14.

Atkin, C. and Merchant, P. (2004). The impact of adult literacy and numeracy levels on small businesses in rural Lincolnshire: a case study, London: DfES/National Research and Development Centre for Adult Literacy and Numeracy.

Atkin, C. and O'Grady, A. (2006a). 'Devaluing Social Networks in the Race to Compete'. International Journal of Learning Vol. 13 Issue 6, pp.165-172.

Atkin, C. and O'Grady, A. (2006b). 'Skills for Life: Has the need to support social cohesion been displaced by the drive for economic success?' International Journal of Adult and Lifelong Education. Vol. 4 No.1-4 pp. 2944.

Atkin, C., Rose, A. and Shier, R. (2005). Provision of, and learner engagement with, Adult Literacy, Numeracy and ESOL support in rural England: a case study. London: DfES/National Research and Development Centre for Adult Literacy and Numeracy.

Barton, D. (1994). Literacy - The Ecology of Written Language, London: Blackwell.

Barton, D. and Hamilton, M. (1998). Local literacies: reading and writing in one community, London: Routledge.

Barton, D. and Tusting, K., (Eds.). (2005). Beyond Communities of Practice: Language, Power and Social Context. Cambridge: Cambridge University Press.

Bourdieu, P. (1998). Practical Reason: On the Theory of Action. Cambridge: Polity Press.

Comings, J., Parrella, A. \& Soricone, L. (1999). Persistence among adult basic education students in pre-GED classes (NCSALL Rep. No. 12).. Cambridge, MA: NCSALL.

DfEE (2001). Skills for Life: the national strategy for improving adult literacy and numeracy skills London: DfEE.

Defra. (2004). New Rural Definition http://www.defra.gov.uk/rural/strategy/annex_a.htm [Accessed 19th February 2007].

Gee, J. P. (1999). An introduction to discourse analysis: theory and method. London: Routledge.

Geertz, C. (1961). 'Studies in Peasant Life: Community and Society' Biennial Review of Anthropology. Vol. 2 pp. $1-41$.

Government Office for the East Midlands. (2007). http://www.goem.gov.uk/goem/our-region/gsi/ [accessed on $19^{\text {th }}$ February 2007].

Jenkins, R. (1998). Pierre Bourdieu. London: Routledge.

Jones, W. (2002). 'Rural adult education in Britain: a historical survey' in Gray, F. (Ed.). Landscapes of learning: Lifelong learning in rural communities. Leicester: National Institute of Continuing Adult Education, 47-65.

Kress, J. R. and Van Leeuwen, T. (2001). Multi multimodal discourse: the modes and media of contemporary communication, London: Continuum Press.

Lewis, I. M. (1985). Social Anthropology in Perspective: The relevance of social anthropology. (2nd Edition). Cambridge: Cambridge University Press.

Lincolnshire Echo. (2010). 'Number of migrant workers in Lincolnshire continues to rise despite economy' (www.thisislincolnshire.co.uk accessed $21^{\text {st }}$ Sept. 2010).

Mahar, C., Harker, R. and Wilkes, C. Eds. (1990). An Introduction to the Work of Pierre Bourdieu: The Practice of Theory. London: MacMillan Press.

Morgan, W. J. and Atkin, C. (2006). 'Overcoming Social Exclusion: Continuing Education as social policy in Britain'. Weiterbildung 3/2006 pp. 36 - 40.

O'Grady, A. and Atkin, C. (2009). 'Skills for Life and Issues of Choice: A Study of Rural England'. RaPAL Journal: Research and Practice in Adult Literacy, Vol. 68-69 (Summer 2009). pg. 40-48. ISSN 1747-5600. 
O'Grady, A. and Atkin, C. (2006). 'Choosing to Learn or Chosen to Learn: the experience of Skills for Life learners'. Research in Post-compulsory Education Vol. 11, No. 3, pp. 277-287.

Papen, U., (2005). Adult Literacy as Social Practice. Oxon: Routledge.

Porter, K., Cuban, S., Comings, J. (2005). 'One Day I Will Make It'; A Study of Adult Student Persistence in Library Literacy Programs, New York: MDRC.

Street, B. (1993). (Ed). Cross-cultural approaches to literacy. Cambridge: Cambridge University Press

Sinclair, P. (2002). 'Leaving or Staying' Ommer, R. (Editor). The Resilient Outport: Ecology, Economy and Society in Rural Newfoundland. St John's, Newfoundland: Memorial University of Newfoundland, Institute of Social and Economic Research. pp.289-318.

Countryside Agency. (2002). Rural proofing - policy makers' check list, Cheltenham, Countryside Agency.

The Countryside Agency (2007). http://www.countryside.gov.uk/LAR/Regions/eastMidlands/activities/research/rsotc/em rsoc map5.asp?article= tcm:2-14824\&pdf1=\&pdf2=tcm:2-16005 [Accessed $19^{\text {th }}$ February 2010].

Young, M., Fleischman, H., Fitzgerald, N. \& Morgan. M. (1994). National Evaluation of Adult Education Programs: Patterns and Predictors of Client Attendance, Arlington, VA: Development Associates.

Table 1. ESOL learners - country of origin

\begin{tabular}{|l|l|l|l|}
\hline Country & Number of learners & Country & Number of learners \\
\hline Afghanistan & 1 & Poland & 1 \\
\hline Angola & 2 & Portugal & 2 \\
\hline Bangladesh & 9 & Romania & 2 \\
\hline Brazil & 3 & Russia & 1 \\
\hline China & 7 & Singapore & 1 \\
\hline Egypt & 1 & Slovakia & 2 \\
\hline Hong Kong & 4 & Solomon Islands & 2 \\
\hline Hungary & 2 & Somalia & 1 \\
\hline India & 1 & Spain & 2 \\
\hline Japan & 4 & Switzerland & 1 \\
\hline Korea & 1 & Thailand & 5 \\
\hline Lithuania & 2 & Tibet & 1 \\
\hline Nigeria & 1 & Turkey & 4 \\
\hline Philippines & 1 & Ukraine & 4 \\
\hline
\end{tabular}

(Atkin, et al., 2005: 60) 


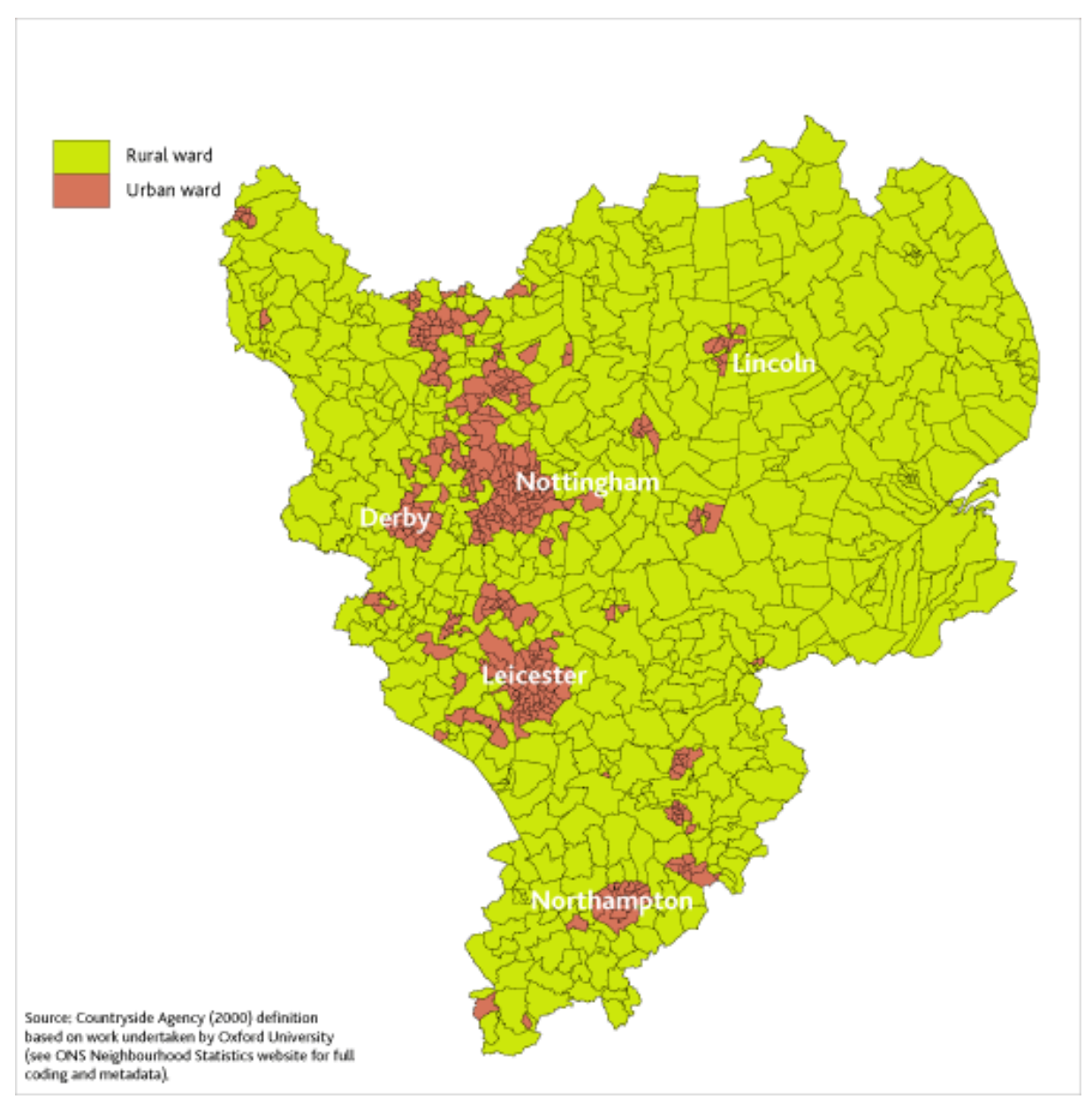

(The Countryside Agency, 2007)

Figure 1. Rural and Urban wards in the East Midlands 